\title{
Research on the Influence of Price Promotion on Consumer Purchase Decision under Network Environment
}

\author{
Tiantian TANG, Liaogang HAO \\ School of Economics and Management, Southwest Jiaotong University \\ 610031,China \\ tangtiantian@126.com
}

Keywords: online shopping, era development, marketing concept, price promotion

\begin{abstract}
With the popularity of the Internet and e-commerce technology matures, the size of China's online shopping users gradually expanded. Online shopping has become an integral part of network life. Online merchants have developed different marketing strategies to maximize the attraction of users, of which the price promotions are obviously favored by the Internet merchants. Keeping pace with the times and choosing the promotion strategy in line with the development of the times will help the online merchants to achieve their own management purposes and create profits. Internet businesses need to update the marketing idea and method is improved rapidly, update the traditional marketing model, the effective use of network marketing to guide more consumers from traditional shopping into online shopping, expand their share of merchandise in the market, combined with the traditional consumer behavior shopping environment theory and price promotion research, launched a deep the Discussion on this subject.
\end{abstract}

\section{Introduction}

Network promotion refers to the use of computers and network technology to transfer information about goods and services to the virtual market, in order to trigger consumer demand, arouse the desire to buy and facilitate the purchase of various activities. Network promotion is through SEO, website promotion, online advertising, marketing events and many other technical methods to do promotion. Network promotion is carried out under the virtual market environment of Internet. As a big network which connects the world's network promotion, it brings together consumers from all over the world and integrates a variety of concepts of life and consumption, showing a new, non geographical, time limited view of space and time. In this environment, the concept of consumers and consumer behavior have undergone great changes.

They generally implement a wide range of choices and rational consumption, many consumers are also directly involved in the production and distribution cycle, therefore, Internet marketers must break through the limitations of the traditional physical market and physical space-time concept, the new thinking method of virtual market, adjust their marketing strategy and implementation plan. Internet virtual market, all enterprises, regardless of their size, are pushed to a unified global market, regional market tradition is gradually being broken, enterprises have to directly face the fierce international competition. If an enterprise does not want to be eliminated, it must learn to do business in this virtual market. Network promotion is the transmission of goods and services through the Internet, the existence, performance, efficacy and characteristics of information.

The multimedia technology provides approximate to the real deal in the process of commodity form, information dissemination, two-way fast mode, will meet each transaction parties expressed most incisive, also for the other full time to think. Price strategy refers to the enterprise through the evaluation of customer demand and cost analysis, select a strategy that can attract customers and achieve marketing mix. The cost of logistics enterprises is complex, including transportation, packaging, warehousing and so on. So the price strategy must be determined to study the laws of 
science as the basis, with practical experience as the means, in the premise of maintaining the economic interests of both producers and consumers, consumers to acceptable levels as a benchmark, flexible response according to the change of the market situation, both common objective decision. When making the first price, the enterprise should consider the following factors: pricing target; determine the demand; estimate the cost; choose the pricing method; select the final price.

\section{Buyer Reaction}

Customers have the following views on the price may be: the old style products, new products will be replaced; products have the disadvantage of poor sales; financial difficulties, it is difficult to continue to operate; prices will fall further; the decline in the quality of products.

The customer may respond to the price increase: the product is selling well; it can not be bought without speed; the product is of great value; the seller wants to make more profits.

Buyers of value of different price responses are different, the value is high, price changes often buy products are more sensitive; and for low value, do not often buy products, even if the unit price is high, buyers do not care. In addition, buyers are usually more concerned with the total cost of acquiring, using and maintaining the product, so the seller can set the price of the product higher than his competitors and make more profits.

\section{Competitor Reactions}

Competitors react to price changes in the following categories: Opposite reactions. If you raise the price, he will raise the price; he will lower the price if you reduce the price. Such consistent behavior, the impact on the enterprise is not too large, will not lead to serious consequences. Enterprises adhere to a reasonable marketing strategy, will not lose the market and reduce market share. Reverse reaction. You raise the price, he depreciates or keeps the original price unchanged; you lower the price; he raises the price or keeps the original price unchanged.

This kind of conflicting behavior, the influence is very serious, the competitor's goal is also very clear, is seizes the opportunity to strive for the market. In this regard, enterprises should investigate and analyze, first of all, to find out the specific purpose of competitors, and secondly, to estimate the strength of competitors, and once again to understand the market competition. Cross reaction. Many competitors have different reaction to the price adjustment of enterprises, there are opposite, reverse, constant, complex situation. When enterprises have to make price adjustments, they should pay attention to improve the quality of their products, strengthen advertising and keep the channels of distribution unblocked.

\section{Corporate Response}

In a homogeneous product market, if competitors reduce prices, companies will have to cut prices, otherwise businesses will lose customers. An enterprise raises its prices, and other firms increase their prices (if the price rises in favour of the industry as a whole), but if an enterprise does not raise the price, the first price increases will have to be lifted and other firms will have to cancel the price increase.

In the heterogeneous product market, buyers not only consider the price level, but also consider the factors of quality, service and reliability, so buyers of small price difference between the non response or not sensitive, the enterprise response to competitors price adjustment more free.

When an enterprise responds, it must first analyze: what is the purpose of the competitor's price adjustment? Is the price adjustment temporary or long-term? Can it last? Enterprises face competitors should weigh gains and losses: should respond? How do you react? In addition, we must analyze the complex problems of price elasticity of demand, the relationship between product cost and sales volume.

In order to respond quickly, it is better to formulate procedures in advance to handle the 
flexibility and effectiveness of the response. With the development of market economy, enterprise marketing faces new challenges, and sales promotion occupies more and more important position in the combination of enterprise marketing strategy. Promotion strategy will have a direct impact on consumer shopping behavior. Under the guidance of specific marketing goals, it is necessary to adopt the necessary marketing strategy and design the most effective promotion tools according to specific circumstances. This study discusses the current promotion strategy, and analyzes the impact of promotion strategy on consumer behavior, so as to provide reference for the smooth development of enterprise marketing.

In fact, promotions include all promotions except advertising, personal promotion, public relations, and direct marketing. Promotion strategy directly affects the consumer perception promotion interests and consumer perception degree will affect consumer attitudes towards the promotion strategy, promotion of consumer attitude determines the behavior intention of consumers to promotion, and thus have an impact on the promotion of brand equity is. Promotion for the business activities of enterprises becomes more and more important, especially has undergone profound changes, the demand characteristics of urban residents social lifestyle and consumer behavior model, from the "thrift, follow the mainstream" single consumption patterns into the pursuit of "value", "fashion", "brand" and "personalized" diversified consumption model. In line with economic development, enterprises have to pay attention to the improvement of promotional behavior.

Significance of sales promotion. Sales promotion directly affect consumers to make changes in the purchase time, brand conversion, increase the amount of purchase, use of alternative products, increase the storage of alternatives. Letting consumers buy better quality products at other prices in other cases, reducing consumer search and decision costs. From an economic point of view, promotions can bring money or non monetary benefits, reduce transaction time and simplify purchasing decisions. Consumers are also easily attracted to certain feelings or emotions and spread promotional information to other consumers.

Promotion strategy. At present, enterprises have adopted a variety of promotional activities, such as discounts, discounts, coupons, rebates, buy gifts, sweepstakes or contest etc., only the following brief introduction in shopping malls in the highest frequency of discounts, coupons, gifts to buy three deals.

Discount promotions. The effect of product promotion is influenced by the type of goods, such as low-priced and storable goods, which are more pronounced for promotional purposes. But the frequency of discounts and the depth of promotion are too high, but it will damage the brand assets, lead to consumers sensitive to prices, weaken the trust of consumers on the enterprise, and have a negative impact on consumer loyalty. Coupon promotions can give consumers more valuable trading value evaluations. Consumers claim to the retailer's product price of conventional a high degree of trust, the coupon is regarded as a permanent decline in the price of signals are less likely than larger discount, the possibility of changing consumer purchase intention.

Buy gifts. Promotional gifts will reduce consumer willingness to pay for key commodities and gifts itself, gifts will be described as free products so that consumers tend to inference "cheap", more seriously, may also have a negative impact on the main products of the brand image and brand attitude. Gift promotions are more likely to stimulate impulse shopping than cash discount promotions.

\section{Consumer Response to Promotions}

Entertainment and profit taking. From the point of view of marketing, promotion itself does not make sense. What is valuable is the reaction of people to sales promotion, and it is not easy to equate promotion with sales promotion. Only when consumers feel benign information stimulation will they work. For businesses, of course, promotional activities can promote consumer purchasing activities, but consumer activities and consumer decision-making is an external manifestation of the complex psychological process affected by various factors. When a person perceives the value of the product by comparing the perceived price of a product to his expected value, it creates a 
willingness to buy. Therefore, the consumer response to promotional activities from a perceived influence the process of purchase, consumers buy goods when the purchase process is divided into the pre attention stage, psychological goods weighing stage, stage of purchasing decision. It is noticed that whether the decision of the product has been influenced or changed has to be taken into consideration when the enterprise implements the promotion behavior.

The choice of promotional behavior. Enterprises need to choose specific promotion tools according to specific promotion targets. If the purpose of the promotion is to allow consumers to produce brand switching behavior, competitors will attract customers, then you should consider the use of price discounts and sample gifts of these two promotional tools. If the main purpose is to accelerate the promotion of goods turnover rate, to allow consumers to buy the product than the plan ahead of time, you should consider the main use of price discount and gift shopping this two kinds of promotional tools. If the promotion is to increase short-term sales, so that consumers increase the amount of a single purchase, we should focus on price discounts this promotion tool. If the main purpose of marketing is to sell a new product or foster consumer brand preference, so that consumers can choose to try the product, price discount, free samples, these three kinds of shopping gift promotion tools.

\section{Conclusion}

The increasingly fierce competition environment makes enterprises think about how to sell their products and turn them into profits. For most products, promotion can be regarded as a better marketing method. There are a variety of promotional strategies has been formed, there are emerging novel ways, but after all, enterprises should choose their own cultural characteristics, and adapt to the modern market demand, in order to achieve the purpose of creating value. Research has shown that price stimuli are among the factors that are most likely to trigger consumer impulse buying. At the same time, price promotion is also one of the most popular marketing incentives for businesses. Price promotions to stimulate consumers or distributors to produce more or more quickly purchase or service, and as a tool for short-term sales incentives, price promotion has become the most frequently used businesses, to stimulate consumer impulsive buying promotions. However, the psychological mechanism of the occurrence, development and implementation of consumer impulse buying is uncertain in the context of price promotion. Therefore, it is of great significance to understand the function mechanism of price promotion on consumer impulse buying, and to determine the influence process of price promotion on impulse buying.

Mental accounting theory in the transaction utility that people will have to evaluate the utility in the transaction process by comparing the actual price and the reference price in the shopping process, and then decide to buy decision for us to have a deeper understanding and provides a new research idea of impulse buying behavior. The utility of the transaction price promotion on consumers' impulse buying behavior mechanism, and explore the moderating effects of impulsivity traits between transaction utility and impulse buying behavior.

Through empirical research, this paper found that price promotion will significantly affect consumers' impulsive buying behavior, and transaction utility had a partial mediating effect between price promotion and impulse buying, the price promotion will be influenced by the consumer transaction utility influence consumer impulse buying, and the bigger the transaction utility can stimulate consumer impulse buying however, impulsivity traits of transaction utility and impulsive buying did not play a regulatory role.

\section{Acknowledgements}

Major Projects of National Natural Science Foundation of China (Grant No. 71090402): Research on the Behaviors of the Participants of Service and Service Strategy under the Network Environment. 
National Natural Science Foundation of China (Grant No. 71002063): Research on the Mechanism and Boundary Conditions of Sales Promotion's Influence on Consumers' Purchasing Decisions and Brand Equity.

\section{Reference:}

[1], Jiang Minghua, Dong Weimin. Research on the impact of price promotion frequency on brand equity. Management world,.2003 (07). (In Chinese)

[2], Xiong Shuchu, Luo Yihui. Influence of open information on customer perceived satisfaction loyalty relationship in retail enterprises. Chinese soft science.2008 (06). (In Chinese)

[3], Wang Xia, Zhao Ping, Wang Gao, Liu Jia. Characteristics of Chinese consumer price tolerance. Journal of psychology,.2004 (05). (In Chinese)

[4] Zhu Yao. Price decision under demand price elasticity and asymmetric effects. China's price.2009 (03). (In Chinese)

[5]Y.M.Su. Modern marketing, consumer behavior patterns. The capital economic and trade university press, China's foreign economic relations and trade publishing2004. (In Chinese)

[6]C.Z.Wang. Consumer behavior. Wuhan university press2003. (In Chinese) 